\title{
Commentary
}

\section{Post Endoscopic Retrograde Cholangiopancreatography Pancreatitis: Bitter Pill for Endoscopists to Swallow}

\author{
H. S. Yashavanth, Mohan Ramchandani \\ Department of Gastroenterology, Asian Institute of Gastroenterology, Hyderabad, Telangana, India
}

Post ERCP pancreatitis (PEP) is the dreaded cholangiopancreatography (ERCP). It occurs in a significant proportion of patients undergoing ERCP. In the current world, though magnetic resonance cholangiopancreatography (MRCP) and endoscopic ultrasound (EUS) have displaced ERCP for diagnosis, it is irreplaceable as a therapeutic intervention. ERCP is the standard of care in the current era for management of pancreaticobiliary disorders, including biliary obstruction, cholangitis, and chronic pancreatitis. It is technically demanding procedure with steep learning curve. Procedure is associated with set of adverse events, occurrence of which is relatively frequent and morbid compared with other endoscopic procedures. Significant preventive measures have been described each one more or less statistically significant; on ground reality, none is full proof; and PEP remains as worst nightmare of endoscopist. Thus, it demands further studies and research in this perspective. The current study helps to throw more light on this. This study is one of the large studies on PEP from the Indian subcontinent, demonstrating that the incidence of PEP remains similar to other races and similar preventive interventions play a role reducing the risk throughout.

It is studied among 1320 patients undergoing ERCP and receiving rectal nonsteroidal anti-inflammatory drug (NSAID) for prevention. PEP occurrence was noted in $5.3 \%$ of patients, with nearly half limited to mild pancreatitis and very few developing severe pancreatitis. There was no mortality. Septic shock and respiratory failure were the common complication noted in the affected group. A significant proportion of patients in mild and moderate PEP group did not receive antibiotic. Kochar et al. reported PEP incidence of 9.7\% and mortality of $0.7 \%$ in a very large meta-analysis

\section{Address for correspondence: Dr. Mohan Ramchandani, Department of Gastroenterology, Asian Institute of Gastroenterology, 6-3-661, Somajiguda, Hyderabad - 500 082, Telangana, India. E-mail: ramchandanimohan@gmail.com}

\footnotetext{
This is an open access journal, and articles are distributed under the terms of the Creative Commons Attribution-NonCommercial-ShareAlike 4.0 License, which allows others to remix, tweak, and build upon the work non-commercially, as long as appropriate credit is given and the new creations are licensed under the identical terms.
}

including 108 randomized controlled trials (RCTs) with $>13000$ patients. Interesting the rate of PEP varied with geographical location with different incidence of PEP of 13\% in North American RCTs compared with $8.4 \%$ in European and $9.9 \%$ in Asian RCTs. ${ }^{[1]}$ This makes this study very important showing the clinical profile and outcomes of Indian patients. This may serve as guidance and reference source for Indian physicians and gastroenterologists.

There are three most frequently used methods of preventing PEP: rectal NSAIDs, pancreatic stents, and hydration. In this study, authors used diclofenac suppository in all patients undergoing ERCP. Prophylactic rectal NSAIDs were effective in preventing ${ }^{[2]}$ and its hypothesized to act by blocking the inflammatory cascade. In a RCT by Elmunzer et $a l^{[3]}$ including 602 patients who were at elevated risk for post-ERCP pancreatitis, patients were assigned to either receive a single dose of rectal indomethacin or placebo immediately after ERCP. About $4.4 \%$ of patients receiving rectal indomethacin developed moderate-to-severe pancreatitis which was significantly lower than rate of pancreatitis in placebo arm (8.8\%). In recently published meta-analysis ${ }^{[4]}$ which included seven RCTs involving 2133 patients showed that rectal NSAIDs decreased the overall incidence of PEP (risk ratio: $0.44 ; 95 \%$ confidence interval: 0.34 $0.57 ; P<0.01)$. The number needed to treat was 11 . They also concluded that there was no difference in efficacy between rectal indomethacin and diclofenac, moreover the timing of administration of rectal NSAIDs, that is, immediate pre-ERCP and post-ERCP also did not alter the results.

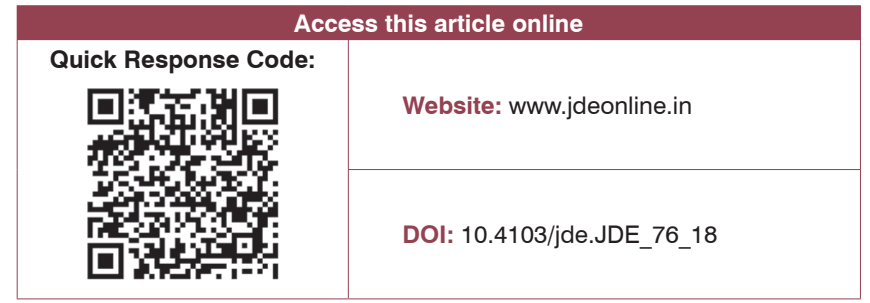

How to cite this article: Yashavanth HS, Ramchandani M. Post endoscopic retrograde cholangiopancreatography pancreatitis: Bitter pill for endoscopists to swallow. J Dig Endosc 2018;9:176-7. 
Aggressive hydration has been shown to lower the rate of PEP. In a randomized double-blind trial conducted by Choi et al., revealed aggressive hydration $(10 \mathrm{ml} / \mathrm{kg}$ Ringer's lactate bolus before and after procedure with $3 \mathrm{ml} / \mathrm{kg} / \mathrm{h}$ during procedure and for $8 \mathrm{~h}$ after the procedure) results in reduction in incidence $(4.3 \%$ vs. $9.8 \%)$ and severity $(0.4 \%$ vs. $2.0 \%)$ of PEP among average and high-risk patients compared to standard hydration group. ${ }^{[5]}$ Anti-inflammatory effect of Ringer's lactate might have an additive effect. It must be used in caution in a patient with volume overload state.

Prophylactic pancreatic stents have long been used as main armamentarium to prevent PEP. Meta-analysis by Fan et al. indicates that it may be possible to prevent PEP by placing a pancreatic duct stent. ${ }^{[6]}$ The mechanism probably involves preserving drainage of the gland and emptying it from reactive pancreatic enzymes. ${ }^{[7]}$ Other preventive measures including protease inhibitors: ${ }^{[8]}$ somatostatin $^{[9]}$ and nitroglycerine ${ }^{[10]}$ require further large-scale studies to prove their place. Initial trials with limited sample size failed to show any benefit of combination pharmacoprophylaxis of rectal indomethacin and bolus lactated Ringer's lactate over rectal indomethacin alone. ${ }^{[1]]}$ Moreover, the combined use of rectal NSAIDs and pancreatic stents has not been shown to be superior than single therapy. ${ }^{[12]}$ Large-scale multicenter RCTs are required to confirm the benefit of combination therapy. Now, it has been proved beyond doubt by high-quality trials that rectal NSAID has a favorable risk-to-benefit profile for PEP, and further studies on this subject should be done with rectal indomethacin as control arm rather than using placebo.

With the advances in EUS, MRCP and risk of PEP, ERCP is no more a diagnostic tool and is utilized as a therapeutic intervention only. Further reduction in the occurrence of PEP can be achieved by careful selection of patients for ERCP, correct implementation of preventive measures, and avoidance of excessive maneuvering in high-risk group. It also demands careful watch and early treatment initiation in case of occurrence.

\section{REFERENCES}

1. Kochar B, Akshintala VS, Afghani E, Elmunzer BJ, Kim KJ, Lennon AM, et al. Incidence, severity, and mortality of post-ERCP pancreatitis: A systematic review by using randomized, controlled trials. Gastrointest Endosc 2015;81:143-9.e9.

2. Elmunzer BJ, Waljee AK, Elta GH, Taylor JR, Fehmi SM, Higgins PD. A meta-analysis of rectal NSAIDs in the prevention of post-ERCP pancreatitis. Gut 2008;57:1262-7.

3. Elmunzer BJ, Scheiman JM, Lehman GA, Chak A, Mosler P, Higgins PD, et al. A randomized trial of rectal indomethacin to prevent post-ERCP pancreatitis. N Engl J Med 2012;366:1414-22.

4. Sethi S, Sethi N, Wadhwa V, Garud S, Brown A. A meta-analysis on the role of rectal diclofenac and indomethacin in the prevention of post-endoscopic retrograde cholangiopancreatography pancreatitis. Pancreas 2014;43:190-7.

5. Choi JH, Kim HJ, Lee BU, Kim TH, Song IH. Vigorous periprocedural hydration with lactated ringer's solution reduces the risk of pancreatitis after retrograde cholangiopancreatography in hospitalized patients. Clin Gastroenterol Hepatol 2017;15:86-920.

6. Fan JH, Qian JB, Wang YM, Shi RH, Zhao CJ. Updated meta-analysis of pancreatic stent placement in preventing post-endoscopic retrograde cholangiopancreatography pancreatitis. World J Gastroenterol 2015;21:7577-83.

7. Freeman ML. Use of prophylactic pancreatic stents for the prevention of post-ERCP pancreatitis. Gastroenterol Hepatol (N Y) 2015;11:420-2.

8. Seta T, Noguchi Y. Protease inhibitors for preventing complications associated with ERCP: An updated meta-analysis. Gastrointest Endosc 2011;73:700-60.

9. Wang G, Xiao G, Xu L, Qiu P, Li T, Wang X, et al. Effect of somatostatin on prevention of post-endoscopic retrograde cholangiopancreatography pancreatitis and hyperamylasemia: A systematic review and meta-analysis. Pancreatology 2018; 18:370-8.

10. Shao LM, Chen QY, Chen MY, Cai JT. Nitroglycerin in the prevention of post-ERCP pancreatitis: A meta-analysis. Dig Dis Sci 2010;55:1-7.

11. Mok SRS, Ho HC, Shah P, Patel M, Gaughan JP, Elfant $\mathrm{AB}$, et al. Lactated ringer's solution in combination with rectal indomethacin for prevention of post-ERCP pancreatitis and readmission: A prospective randomized, double-blinded, placebo-controlled trial. Gastrointest Endosc 2017;85:1005-13.

12. Akbar A, Abu Dayyeh BK, Baron TH, Wang Z, Altayar O, Murad MH, et al. Rectal nonsteroidal anti-inflammatory drugs are superior to pancreatic duct stents in preventing pancreatitis after endoscopic retrograde cholangiopancreatography: A network meta-analysis. Clin Gastroenterol Hepatol 2013;11:778-83. 